\title{
SA Journal of Industrial Psychology: Annual editorial overview 2019
}

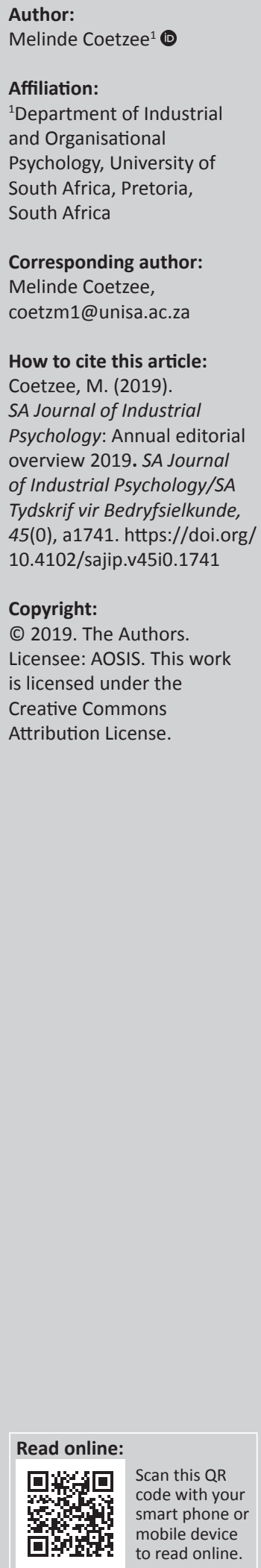

This article is intended to provide an overview of the publication themes of the 45th edition of the SA Journal of Industrial Psychology (SAJIP) (2019). Guidelines and suggestions for improving future editorial matters are also provided.

Keywords: SAJIP editorial; reproducibility and replicability in open science practices; quantitative research; qualitative research; theory building in research; manuscript review processes; research in industrial and organisational psychology; applied psychology.

\section{Introduction}

This 45th edition of the SA Journal of Industrial Psychology (SAJIP) marks an important period of transition. Firstly, the 45th year of the journal heralds SAJIP's inclusion in the International Bibliography of the Social Sciences' (IBSS) index list of reputable scientific journals that serve as essential online resources for social science and interdisciplinary research. This wonderful achievement is good news for both the journal and its authors, as it signifies the potential increase in the impact factor of the journal and its publications. This inclusion of the SAJIP on the IBSS index confirms the SAJIP as an established, reputable well-founded venue for high-level scholarship on the science and practice of industrial and organisational psychology upon which the SAJIP can build. Over the years, the SAJIP has developed a reputation for publishing scholarly work of high relevance in the broad field of applied psychology, and in particular, scientific work relevant to the South African organisational context. The published works are generally considered rigorous by academic scholars and relevant by practitioner communities. Some figures, at the time of writing this editorial, support this view:

1. The number of new submissions increased from $2015(n=58)$ to $2019(n=90)$.

2. Desk pre-screening and post-reviews have become more rigorous with an increase in the rejection rate: pre-screening (2015: $n=25 ; 2019: n=43)$ and post-review $(2015: n=7 ; 2019$ : $n=13$ ). The average desk rejection rate for the period $2015-2019$ was $46 \%$, and the average post-review rejection rate was $13 \%$.

3. The SAJIP publication rate per annum is on average a steady 25 articles.

4. The crossref citations have increased from $n=78$ (2015) to $n=364$ (2019).

After 45 years of existence, the journal remains lively and in good shape. It is through the sustained efforts of the previous and current editors, associate editor, section editors, authors, AOSIS editorial assistants and, not the least, the peer reviewers, that the SAJIP has gained the position that it enjoys today.

Secondly, this edition marks the end of my role as the Editor-in-Chief (2014-2019) of the SAJIP. It has been a blessed honour and privilege to have served the SAJIP and working together with a strong outstanding team of section editors, editorial board members, peer reviewers and the highly valued esteemed staff of AOSIS who all supported me in their professional capacity throughout the period 2014-2019. I would like to express my sincerest gratitude towards each individual of the SAJIP editorial team and acknowledge their great work for ensuring the publication of high quality scholarly articles. All members of the section editorial board and also the peer reviewers of manuscripts provided a key contribution through constructive feedback, detailed comments and quick turnaround times of manuscripts. My gratitude is also extended to the authors who chose the SAJIP as their preferred outlet for considering their valued research for publication review and by doing so, helped to build the standing of the journal. As scholars in the broad field of applied psychology, the original works submitted by authors are a key resource of the journal. The authors both supply articles that are eventually published (i.e. if they pass the rigorous editorial screening and peer review processes), and, at the same time, contribute to the SAJIP's mission as a forum for cutting-edge, peer-reviewed research in all fields related to investigations into the ways in which individuals can balance their daily activities 
(socially, culturally or linguistically) against the larger context of corporate, organisational and institutional values. Last but not the least, I was also blessed to be supported by the associate editor, Prof. Llewellyn van Zyl, who always brought quality initiatives to the table to further the standing and impact of the SAJIP. One such initiative is the SAJIP historical landmark special section (see this edition) on reproducibility and replicability in open science practices and methodological improvements for future editions of the SAJIP. This special collection will open up new avenues for research and publication practices to be considered by the new Editor-in-Chief.

Thirdly, the SAJIP welcomes the new leadership of Professor Crystal Hoole (University of Johannesburg) who will take over the role as Editor-in-Chief from 2020. It has been a wonderful and exciting journey for me in taking the lead and working together with the editorial and AOSIS team for 6 years to bring the SAJIP forward. I feel happy and fortunate to leave the leadership of such a rigorous and relevant journal in the hands of an esteemed scholar in the field of industrial and organisational psychology. I feel confident that in Prof. Hoole's good hands, and with the continued support of the editorial board members and AOSIS staff, the SAJIP will continue to grow its impact for a bright and ever-upwards future.

In this farewell editorial, I would like to highlight key themes that were the focus of scholarly works published in the SAJIP 2019. These themes are then compared with the current (2019) dominant scientist-practitioners' themes presented at the 21st Annual Society for Industrial and Organisational Psychology South Africa (SIOPSA) Conference and key 2019 themes published by international scholars who are either practising and have made enduring contributions of high impact in the organisational psychology and organisational behaviour domains (as recognised by the high-impact scientific journal Annual Review of Organizational Psychology and Organizational Behavior). In addition, I would like to comment on the opinion paper by Efendic and Van Zyl (2019: see the special collection in this SAJIP edition on the reproducibility and replicability in open science practices), including the rebuttal papers, by identifying some key challenges and suggesting future directions for the SAJIP.

\section{Overview of key SA Journal of Industrial Psychology themes: 2019}

Table 1 provides an overview of the key themes of articles published in the SAJIP's 45th (2019) issue in comparison with the dominant themes evident in the Annual Review of Organizational Psychology and Organizational Behavior (2019) and the presentations at the 21st Annual SIOPSA Conference (2019).

The various scholarly themes are clustered into seven core domains:

1. scale development and measurement of individual and organisational behaviour
2. mental health themes as reflected in the SAJIP special collection section with guest editor Professor Willie T. Chinyamurindi. The SAJIP mental health section contributed to World Mental Health Day 10 October 2019

3. themes pertaining to diversity

4. themes concerning the psychosocial domain of individual behaviour in organisations

5. organisational practices affecting the psychosocial wellbeing, satisfaction and performance of individuals

6. themes pertaining to the societal context of people's behaviour

7. issues pertinent to the scientist-practitioner role of scholars in the applied field of psychology, industrial and organisational psychology, and work and organisational behaviour.

Apart from measurement and scale development that remain an essential common focus of industrial and organisational psychology (IOP) scholars as scientist-practitioners, themes relating to the psychosocial factors and organisational practices influencing human behaviour, well-being and performance remain a niche domain of interest to these scholars. With regard to the SAJIP, the psychosocial themes of workplace flourishing and thriving received the highest frequency of abstract and article views for 2019. In general, for the period 2017-2019, the psychosocial theme of jobdemands resources seems to remain the most popular topic to be crossref cited (see Demerouti \& Bakker, 2011) with 11207 abstract views and 49649 article views to date.

Noteworthy is the trend of presentations by scholars and practitioners at the annual SIOPSA conference taking a futuristic view of IOP and positioning the domain themes of the field in the digital workplace space of Industry 4.0. Theme trends at the annual SIOPSA conferences are important to monitor because they reflect especially the practitioners' view of current shifts in industry and society and how these may potentially influence individual and organisational behaviour and performance. IOP practitioners play an important role in reminding academic scholars to stay in tune with real-life contextual issues and the concomitant concerns and needs of organisational decision-makers that require the rigorous scientific research activities of inquiry by the IOP academic scholarly community. As a benchmark for emerging scientist-practitioners' focus areas that require scientific inquiry, the annual SIOPSA conference themes reiterate the importance for scholars to devote greater attention to the influence of contextual situations on IOP theories, constructs and measures. In this regard, it may become increasingly important for scholars to contextualise their IOP research in the domain of the digital workspace (4th Industrial Revolution) in order to ensure that their research remains relevant for scientist-practitioners whose scientific inquiry of interest is embedded in evolutionary and revolutionised digital organisational settings.

Similar to the previous issues of the SAJIP, it is evident from Table 1 that the journal tends to yield a diversity of authors and topics which, in line with the scope of the SAJIP, have 


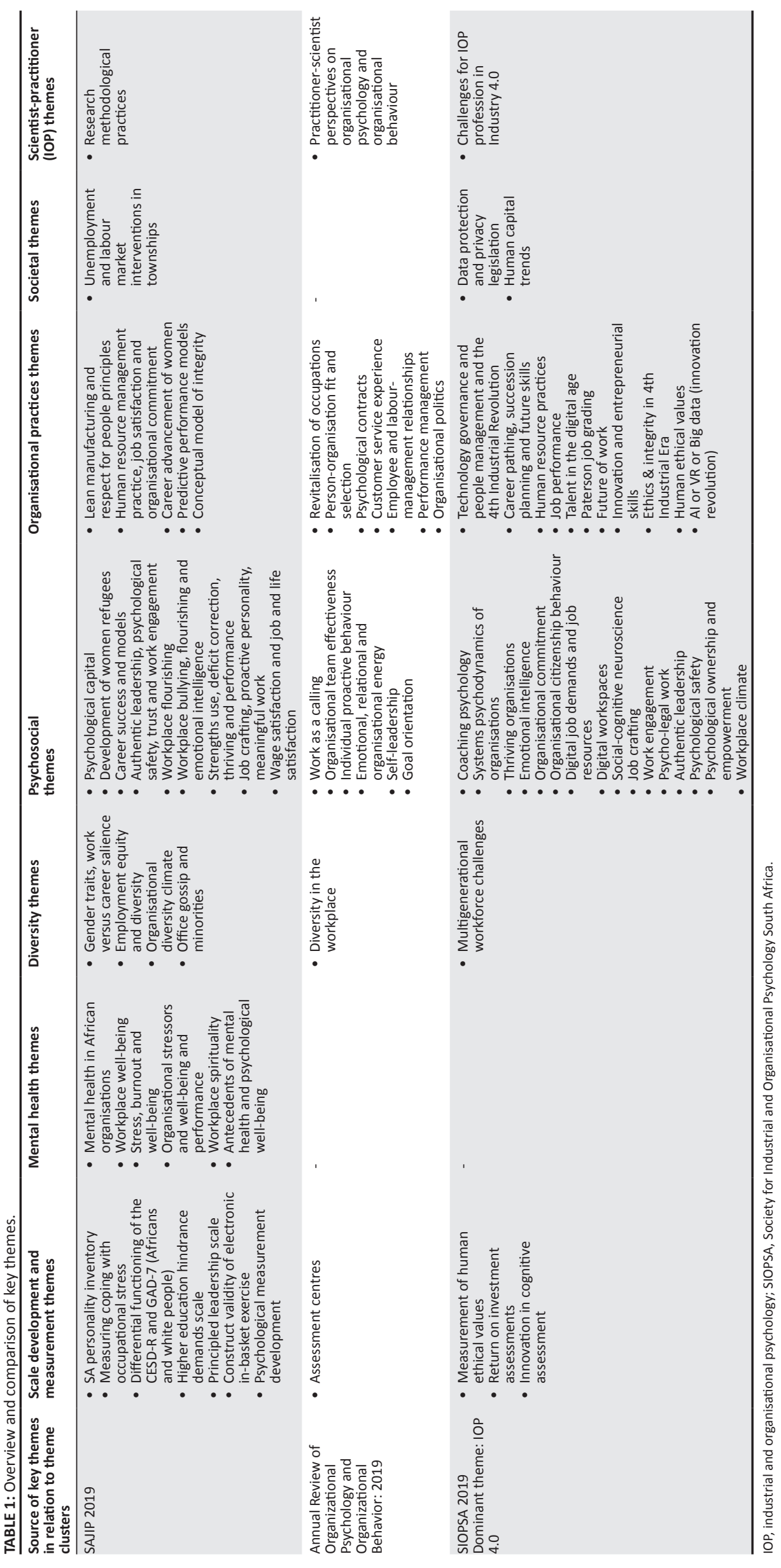


at their core the well-being and dignity of people at heart. The themes reflected in Table 1 mirror some of the recommendations made in the manifesto by European scholars for ensuring a sustainable future for the field of work and organisational psychology (Bal et al., 2019). Scholars and practitioners in the field of applied psychology should acknowledge their responsibilities towards individuals by keeping in mind the well-being of individuals when engaging in activities of scientific inquiry. The psychosocial well-being of individuals should also be placed at the centre of management and organisational practices; work should be organised in ways that protect the health of employees. Moreover, scholars and practitioners need to remain critical about how their research and work impact society at large whilst keeping societal interests in mind when pursuing research endeavours. The need of employees' mental health and optimal well-being and dignity should be placed at the forefront of such research endeavours. Scholars should describe the implications of their research in their publications and recommend evidence-based practices that promote the well-being, integrity and dignity of employees in their current and potential future work settings (Bal et al., 2019).

\section{Editor's comments: Special collection on reproducibility and replicability in open science practice}

The opinion paper by Efendic and Van Zyl speaks about the recent calls for more robust science practice in psychological research, and for scientific journals to publish research that has value, is valid and is analytically reproducible and replicable. The authors' article offers useful insights into the evolving requirements and expectations stipulated for robust methodological rigour in the planning, execution and writing up of quantitative research of which the SAJIP editorial team, peer reviewers and potential authors need to take note of. Their arguments are sensitive to potential issues that contribute to the so-called replication crisis in IOP which alludes to the current concerns about lack of statistical power and small samples, publication bias (i.e. the trend towards reporting only significant rather than non-significant effects), publication pressure from the academia community and lack of transparency (i.e. access to data or materials) in open science publishing. Efendic and Van Zyl offer some practical guidelines for policy makers, editorial staff and prospective authors of the SAJIP regarding matters concerning statistical power, sample size, significance levels and employing bestpractice guidelines for statistical analyses and reporting. In order to enhance the transparency and credibility of a research study, the authors recommend the practice of 'preregistration' (i.e. authors preregister their studies, including the research design, sampling, analytical plans and procedures within the parameters of local ethical and data protection rules and protocols). The rebuttal papers offer insightful reflection on the arguments and recommendations made by Efendic and Van Zyl, and provide additional constructive suggestions that could potentially help to increase the robustness of scientific work published in the SAJIP. The rebuttal papers further add unique perspectives on factors contributing to the complexities of the replication crisis that Efendic and Van Zyl so eloquently illustrated in their article.

A golden thread that seems to run through Efendic and Van Zyl's paper and the rebuttal papers is the imperative for methodological rigour as a means for confirming integrity, credibility and the legitimacy of the research process and results. Apart from a manuscript not showing a clear match with the journal's scope, the SAJIP manuscript rejections generally relate to matters of concern regarding methodological rigour which include, inter alia, a lack of sound theoretical contextualisation of the research problem, unclear research objectives, poorly formulated research hypotheses or propositions, research design flaws, sampling (i.e. too small), suboptimal instrumentation, poor writing and organisation, lack of compliance with the SAJIP bestpractice guidelines for quantitative and qualitative study designs, unreliable or incomplete data and lack of originality. In this regard, Efendic and Van Zyl make an urgent call to the SAJIP to consider raising the bar in setting higher standards for evaluating the methodological rigour of manuscripts that fall within the quantitative research paradigm. As rightfully pointed out by Efendic and Van Zyl, quantitative research focuses on replication, reproducibility and internal and external validity of research which may be enhanced by considering the suggestions outlined in the opinion and rebuttal papers section of this issue of the SAJIP.

Reviewing manuscripts for potential publication in a journal such as the SAJIP remains complex and multifaceted. Latham (2019) reminds the IOP scholar that research in the applied psychology domain should be anchored in empirical reality, that is, empirical findings (whether quantitative and/or qualitative) should increase the scientist-practitioner's ability to predict, understand and influence organisational behaviour. Statistical and other empirical methods should not drive the research process to the extent that research problems reflect what is possible to study with sophisticated statistical and/or empirical techniques at the expense of figuring out what should be studied to bring solutions to real-life human behavioural problems and issues, and then develop new, appropriate and robust scientific methods for such studies. However, on the other hand, practitioners need to develop an appreciation for the scientific and methodological rigour of scholarly research and the highly sophisticated statistical and other empirical techniques employed by scholars to advance theory and produce new knowledge in a valid and credible manner. Ultimately, the scientist-practitioner foundation of the IOP field requires journal publications to demonstrate evidence that highly sophisticated theory and robust empirical techniques have led to context-relevant innovative or useful practice (Latham, 2019). 


\section{Recommendations for consideration}

It may serve the SAJIP editorial team well to use their discretion in heeding the suggestions (made by Efendic and Van Zyl and the authors of the rebuttal papers) pertaining to manuscripts in the quantitative research paradigm. It should be noted that the SAJIP also welcomes manuscripts anchored in the qualitative research domain. Similar to quantitative research design, manuscripts in the qualitative research domain also serve a valuable purpose in elaborating on, advancing and building IOP theory through the application of methodological rigour.

A study's research methodological design may be driven by pre-existing conceptual ideas, theoretical premises or a preliminary conceptual model. New theory generation generally flows from a research inquiry that produces formal and testable propositions which could potentially also be tested in the form of quantitative research hypotheses in follow up studies. Theory testing is often seen as the domain of quantitative research because of the research design being driven by the testing of formal research hypotheses or a formal theory. In the broader knowledge creation process, both quantitative and qualitative research contribute through robust scientific methodological inquiry to theory generation (i.e. deductive or inductive creation of new theory) and theory testing (i.e. assessing whether and under which conditions a theory holds up empirical scrutiny). In this regard, Efendic and Van Zyl's arguments are important to consider when evaluating the validity and credibility of new knowledge or theory generation and/or elaboration by means of quantitative research designs. However, some additional aspects that could be considered by the SAJIP (for both quantitative and qualitative research designs) include matters pertaining to theory advancement and empirical adequacy: the manuscript provides evidence of construct clarity and validity (i.e. constructs must be clearly defined, conceptualised and contextualised); constructs clearly reflect the phenomenon in question (i.e. the constructs are distinguishable from other similar constructs and compared with the application of the construct theory across different settings). The implicit or explicit logic of proposed relations is clearly specified and clearly aligned with empirical observations (i.e. the structuring of theoretical and empirical relations improve the explanatory potential and predictive adequacy of an existing theory). The study considers the extent to which existing theoretical insights fit into a context different from that for which it was developed. Researchers need to acknowledge the limitations of their research design and those of the unique boundary of the theoretical perspective in which the study is anchored (see Fisher \& Aguinis, 2017).

\section{Conclusion}

Over the years, the goal of the SAJIP was to encourage prospective authors (both established researchers, as well as developing researchers) to submit scientifically sound, relevant, original and methodological rigorous research that focuses on the importance of the research question, the rigour of the research design (i.e. quantitative and/or qualitative), innovative cost-effective data gathering and robust scientific data analysis that leads to consequential findings, a testable theory and new knowledge and theory generation, advancement or theory elaboration. Ultimately, results and findings should be credible and valid, and the content of the manuscript must contain a clear, relevant, useful and exciting new scientific message that advances IOP theory and practice. It is my hope, as the present Editor-in-Chief, that SAJIP will continue to serve the scholarly community in providing a platform for publishing robust and credible IOP research. However, it is acknowledged that although the SAJIP has made great strides in terms of promoting and showcasing relevant IOP science and research, more efforts must be made to ensure that the journal's editorial and review practices keep pace with evolving criteria for scientific rigour in the applied psychology field. In nearing the completion of my term as the Editor-in-Chief, I hope that, given the specific guidelines and recommendations offered in the opinion and rebuttal papers, and in this 2019 editorial overview, the number of scholars taking advantage of the diverse perspectives on improving the methodological rigour of their research practices may increase substantially. It is believed that the SAJIP community will collectively tackle the issues that may impede the credibility and validity of their research. May the SAJIP grow in its strength as a vibrant platform for displaying robust IOP scientific practice in new knowledge production that benefits people in organisations and communities.

\section{Acknowledgements}

\section{Competing interests}

The author has declared that no competing interests exist.

\section{Author's contributions}

M.C. is the sole author of this research article.

\section{Ethical consideration}

This article followed all ethical standards for a research without direct contact with human or animal subjects.

\section{Funding information}

This research received no specific grant from any funding agency in the public, commercial or not-for-profit sectors.

\section{Data availability statement}

Data sharing is not applicable to this article as no new data were created or analysed in this study.

\section{Disclaimer}

The views and opinions expressed in this article are those of the author and do not necessarily reflect the official policy or position of any affiliated agency of the author. 


\section{References}

Bal, P.M., Dòci, E. Lub, X., Van Rossenberg, Y.V.T., Nijs, S., Achnak, S. ... Van Zelst, M (2019). Manifesto for the future of work and organizational psychology. European Journal of Work and Organizational Psychology, 28(3), 289-299. https://doi.org/1 0.1080/1359432X.2019.1602041

Demerouti, E., \& Bakker, A.B. (2011). The Job Demands-Resources model: Challenges for future research. SA Journal of Industrial Psychology/SA Tydskrif vir Bedryfsielkunde, 37(2), Art. \#974, 9 pages. https://doi.org/10.4102/sajip. v37i2.974
Efendic, E., \& Van Zyl, L.E. (2019). On reproducibility and replicability: Arguing for open science practices and methodological improvements at the South African Journal science practices and methodological improvements at the South African Journal
of Industrial Psychology, 45(0), a1607. https://doi.org/10.4102/sajip.v45i0.1607

Fisher, G., \& Aguinis, H. (2017). Using theory elaboration to make theoretical advancements. Organizational Research Methods, 20(3), 438-464. https://doi. org/10.1177/1094428116689707

Latham, G.P. (2019). Perspectives of a practitioner-scientist on organizational psychology/ organizational behavior. Annual Review of Organizational Psychology and Organizational Behavior, 6(1), 1-16. https://doi.org/10.1146/annurev-orgpsych-012218-015323

SIOPSA. (2019). Conference programme $22-24$ July 2019. Pretoria: CSIR, SIOPSA. 